\title{
Effect of commercial or depurinized milk on rat liver growth-regulatory kinases, nuclear factor-kappa B, and endonuclease in experimental hyperuricemia: Comparison with allopurinol therapy
}

\author{
G. Kocic,${ }^{* 1}$ R. Pavlovic, $†$ G. Nikolic, $†$ A. Veljkovic, ${ }^{*}$ S. Panseri, $\ddagger$ L. M. Chiesa, $\ddagger$ T. Andjelkovic, $\S$ \\ T. Jevtovic-Stoimenov, ${ }^{*}$ D. Sokolovic, ${ }^{*}$ T. Cvetkovic, ${ }^{*}$ S. Stojanovic, ${ }^{*}$ H. Kocic,\# and R. Nikolic \\ *Department of Biochemistry, and \\ †Department of Chemistry, Medical Faculty, University of Nis, Nis 18000, Serbia \\ ‡Department of Veterinary Medicine, University of Milan, Milan 20121, Italy \\ $\S$ Department of Chemistry, Faculty of Science, University of Nis, Nis 18000, Serbia \\ \#Medical Faculty, University of Maribor, Maribor 2000, Slovenia
}

\section{ABSTRACT}

Hyperuricemia is a biochemical hallmark of gout, renal urate lithiasis, and inherited purine disorders, and may be a result of enormous ATP breakdown or purine release as a result of cardiovascular disease, hypertension, kidney disease, eclampsia, obesity, metabolic syndrome, psoriasis, tumor lysis syndrome, or intense physical training. The beneficial role of dairy products on hyperuricemia management and prevention is well documented in the literature. The primary aim of our experimental study was to examine the effect of milk dietary regimen (commercial $1.5 \%$ fat UHT milk or patented depurinized milk) compared with allopurinol therapy on experimental hyperuricemia induced by oxonic acid in rats. Principal component analysis was applied on a data set consisting of 11 variables for 8 different experimental groups. Among the 11 parameters measured (plasma uric acid and the liver parameters NFkB-p65, Akt kinase/phospho-Akt kinase, ERK kinase/phospho-ERK kinase, IRAK kinase/phospho IRAK kinase, p38/phospho-p38, and DNase), Akt/ phospho Akt and ERK/phospho-ERK signaling were extracted as the most discriminating. We also compared the content of various potentially toxic compounds (sulfur compounds, ketones, aldehydes, alcohols, esters, carboxylic acids, and phthalates) in untreated commercial milk and depurinized milk. Of all the compounds investigated in this study that were observed in commercial milk (24 volatile organic compounds and 4 phthalates), 6 volatile organic compounds were not detected in depurinized milk. For almost all of the other compounds, significant decreases in concentration were

Received August 25, 2013.

Accepted January 26, 2014.

${ }^{1}$ Corresponding author: kocicrg@yahoo.co.uk observed in depurinized milk compared with commercial milk. In conclusion, a depurinized milk diet may be recommended in nutritional treatment of primary and secondary hyperuricemia to avoid uric acid and other volatile, potentially toxic compounds that may slow down liver regeneration and may induce chronic liver diseases.

Key words: milk, hyperuricemia, nuclear factor kappa $\mathrm{B}(\mathrm{NF} \kappa \mathrm{B})$, Akt kinase

\section{INTRODUCTION}

A significant number of dietary chemicals are volatile, potentially toxic compounds, capable of altering the human genome by changing gene structure, leading to monogenic or polygenic mutations and DNA rearrangements, or by changing gene regulation, leading to disregulation and altered gene expression. Such changes, in turn, may affect concentration and conformation of cell and extracellular matrix proteins, alteration of enzyme activity, concentration and function of structural proteins, or alteration of cell signalization (Kaput, 2004). Some regulatory genes may be dietsusceptible and may have a crucial role in alteration of signal transduction, cell cycle activity, proliferation, or apoptosis. In this way, regulatory genes may play a role in the disregulation of regenerative tissue potential, leading to development, progression, or increased severity of chronic diseases. Nutraceuticals are defined as functional food products capable of providing medical or health benefits, including the prevention and treatment of diseases. Many ingredients may be successfully incorporated in nutraceuticals but it might be difficult to omit undesirable, and potentially toxic, compounds. Concerning the milk-derived functional elements, biologically active peptides and whey proteins (lactoferrin, lactoperoxidase, lysozyme, and immunoglobulins) are 
currently proposed by Séverin and Wenshui (2005) as complementary components of standard therapy in the treatment of diarrhea, hypertension, thrombosis, dental diseases, mineral malabsorption, and immunodeficiency because of their immunological protective properties. Except for lactose-free and fat-free milk derivatives, no other functional milk products, with potentially harmful compounds eliminated, are commercially produced.

Primary hyperuricemia is implicated in disorders such as gout, renal urate lithiasis, and inherited purine disorders (Sculley et al., 1992; Obermayr et al., 2008; Cheng et al., 2010). Secondary hyperuricemia is thought to appear as a result of enormous ATP breakdown or purine release associated with severe tissue damage, cardiovascular disease, obesity, metabolic syndrome (Feig et al., 2008), hypertension (Saito et al., 1978), kidney diseases (Obermayr et al., 2008), eclampsia (Bainbridge and Roberts, 2008), psoriasis (Goldman, 1981), or tumor lysis syndrome (Davidson et al., 2004). The effects of hyperuricemic conditions on liver tissue functional and regenerative capacity are relatively unknown, even though changes in morphological features were documented by Petta et al. (2011). In all cases of hyperuricemia, a "low purine" diet is usually recommended (Choi et al., 2004; Sauer et al., 2011), comprising presumably a dietary restriction of animal food, such as meat, poultry, fish, or seafood. Dalbeth et al. (2010) documented a beneficial role of dairy products in management and prevention of hyperuricemia. During the process of milk homogenization, most milk purine ribonucleotides are degraded to uric acid due to the activity of xanthine oxidase liberated from milk fat globules. For that reason, almost all milk ribonucleotides become waste products, and commercial milk usually contains significant concentrations of uric acid (UA), as reported by Tiemeyer et al. (1984) and Indyk and Woollard (2004). We have patented technological procedures (Kocic et al., 2010; Carluccio and Kocic, 2011; Cencic et al., 2011) and filter device systems (Kocic et al., 2011) for the production of depurinized (DP) milk almost free of purine nucleotides and UA. In our previous study (Kocic et al., 2012), we showed quantitative evidence of the positive effect of a DP milk diet on serum UA, lipid status, inflammatory markers, hematological parameters, and stem cell potential in rats. Because the depurinization procedure may also eliminate other potentially harmful compounds (e.g., nonpolar hydrophobic aromatic and aliphatic anions), it is of interest to investigate possible beneficial effects of DP milk on tissue regenerative and antiapoptotic potential.

In their studies, Wada and Penninger (2004), Ilowski et al. (2010), and Hers et al. (2011) noted that protein kinases, such as Akt kinase (protein kinase B,
PKB), p38 mitogen-activated protein (MAP) kinase, extracellular signal-regulated kinase (ERK), and IL-1 receptor-associated kinase (IRAK), were the most important downstream effectors of liver regenerative potential. Sequential activation of these protein kinases in response to a variety of extracellular (epigenetic) stimuli may change their phosphorylation status and functional activity on cell transcription factors, cytoskeleton proteins, downstream kinases, and some other regulatory enzymes that are responsible for proliferative activity, intermediary metabolism, protein turnover, or DNA fragmentation (Scheving et al., 2008). The epigenetic aberrations of kinase signaling have been documented in cancer, apoptosis, or inflammation ( $\mathrm{Lu}$ and $\mathrm{Xu}, 2006$ ).

Phthalates are widely used as plasticizers in food packaging materials and their ability to migrate from packaging into foods has been documented by the Scientific Committee on Food (1999). Dietary intake from contaminated food is likely to be the major single source of phthalate exposure in the general population.

The primary aim of our current experimental study was to examine the effect of milk dietary regimen (commercial $1.5 \%$ fat UHT milk compared with depurinized milk) compared with allopurinol therapy on experimental hyperuricemia induced by oxonic acid in rats. To identify mechanisms involved in possible liver regenerative responses, our results were compared in groups of rats fed standard dietary chow and hyperuricemic rats fed standard dietary chow and receiving allopurinol. We hypothesized that the diet regimen, as an epigenetic factor, may modulate growth-regulatory kinases (Akt kinase, ERK, and IRAK), oxidant-sensitive transcriptional factor nuclear factor kappa B $(\mathbf{N F \kappa B})$, and endonuclease activity, which may affect liver regenerative potential. In addition to establishing the UA and purine-pyrimidine profile, we analyzed DP milk and commercial, untreated $1.5 \%$ fat UHT milk (control milk) for potentially toxic volatile compounds that may affect the liver regeneration signaling pathway. Monitoring of milk for phthalate contamination is especially important because milk is a primary food source, especially for children. Phthalate esters were selected for the study, because they are the most common phthalate contaminants in food.

\section{MATERIALS AND METHODS}

\section{Depurinized Milk Production}

Commercial UHT cow milk with $1.5 \%$ fat content was purchased from Niska Mlekara AD (Niš, Serbia). Technological procedures and the filter device system used to produce milk with a reduced level of UA and 
purines (DP milk) were patented at the Institutes for Intellectual Property in Serbia, Slovenia, and Italy (Kocic et al., 2010; Carluccio and Kocic, 2011; Cencic et al., 2011), where the procedures were explained in detail. A health and safety certificate for DP milk was obtained from the public health center in Niš (Serbia). Nutritional composition of milk samples (proteins, carbohydrates, and lipids) was also determined at the public health center. The DP milk samples did not differ significantly from the untreated commercial milk samples.

\section{HPLC Determination of UA in Milk Samples}

To measure UA (the most abundant purine compound in milk), the milk proteins were precipitated, centrifuged, and filtered. Briefly, ice cold perchloric acid $(0.75 \mathrm{~mL}, 8 \% \mathrm{vol} / \mathrm{vol})$ was added to milk samples (1.5 $\mathrm{mL}$ ), which was mixed, allowed to stand for $15 \mathrm{~min}$, mixed, and then centrifuged. After precipitation of the protein fraction $\left(\right.$ at $1,800 \times g, 10 \mathrm{~min}, 4^{\circ} \mathrm{C}$ ), insoluble perchlorate was formed by addition of $2 \mathrm{M} \mathrm{K}_{2} \mathrm{CO}_{3}$ in 6 $M \mathrm{KOH}$ to the supernatant in a quantity sufficient to neutralize the $\mathrm{pH}$ of the samples. Following centrifugal removal of the perchlorate $\left(1,800 \times g, 10 \mathrm{~min}, 4^{\circ} \mathrm{C}\right)$, an aliquot of the supernatant was filtered through a 0.45 $\mathrm{mm}$ syringe filter. Uric acid was determined in remaining supernatant using the HPLC-diode-array detection (DAD) method explained in our previous work (Kocic et al., 2012).

\section{Headspace Solid-Phase Microextraction of Milk Samples}

All milk samples were subjected to the headspace solid-phase microextraction (SPME) procedure developed by Panseri et al. (2011) for the analysis of volatile organic compounds. In brief, the milk samples were treated by weighing exactly $10 \mathrm{~mL}$ of milk into a 20-mL glass vial fitted with a cap equipped with silicon-polytetrafluoroethylene septum (Supelco, Bellefonte, PA) and adding $10 \mu \mathrm{L}$ of 3-methyl-2-pentanone (internal standard, IS) solution in water $(20 \mu \mathrm{g} / \mathrm{mL})$. A temperature of $4^{\circ} \mathrm{C}$ was selected as extraction and equilibration temperature to prevent possible matrix alterations and hydroperoxide decomposition. To keep the temperature constant during analysis, the vials were maintained in a cooling plate (CTC Analytics, Zwingen, Switzerland). At the end of the sample equilibration time $(1 \mathrm{~h})$, a conditioned $\left(1.5 \mathrm{~h}\right.$ at $\left.280^{\circ} \mathrm{C}\right) 85 \mu \mathrm{m}$ carboxen/polydimethylsiloxane (CAR/PDMS) StableFlex fiber (Supelco) was exposed to the headspace of the samples for analyte extraction (180 $\mathrm{min}$ ) by CombiPAL system injector autosampler (CTC Analytics).

\section{GC-MS Analysis of Milk Samples}

The GC-MS analyses were developed by Soncin et al. (2009) and were performed with a Trace GC Ultra coupled to a Trace DSQII quadrupole mass spectrometer (Thermo-Fisher Scientific, Waltham, MA) and equipped with an Rtx-Wax column $(30 \mathrm{~m} \times 0.25 \mathrm{~mm}$ i.d., 0.25- $\mu \mathrm{m}$ film thickness; Restek, Bellefonte, PA). Oven temperature program was as follows: from $30^{\circ} \mathrm{C}$, hold $8 \mathrm{~min}$, to $60^{\circ} \mathrm{C}$ at $4^{\circ} \mathrm{C} / \mathrm{min}$, then from $60^{\circ} \mathrm{C}$ to $160^{\circ} \mathrm{C}$ at $6^{\circ} \mathrm{C} / \mathrm{min}$, and finally from 160 to 200 at $20^{\circ} \mathrm{C} /$ min. Helium was used as a carrier gas at flow rate of $1 \mathrm{~mL} / \mathrm{min}$. Carryover and peaks originating from the fiber were regularly assessed by running blank samples. After each analysis, fibers were immediately thermally desorbed in the $\mathrm{GC}$ injector for $5 \mathrm{~min}$ at $250^{\circ} \mathrm{C}$ to prevent contamination. Ion source temperature was $250^{\circ} \mathrm{C}$. The mass spectra were obtained by using a mass selective detector with the electronic impact at $70 \mathrm{eV}$ and a multiplier voltage of $1,456 \mathrm{~V}$; data were collected at a rate of $1 \mathrm{scan} / \mathrm{s}$ over the mass:charge $(\mathrm{m} / z)$ ratio ranging from 30 to 350 . Compounds were identified by comparing the retention times of the chromatographic peaks with those of authentic compounds analyzed under the same conditions. The identification of MS fragmentation patterns was performed either by comparison with those of pure compounds or by using the National Institute of Standards and Technology (NIST) MS spectral database (NIST spectra library program version 2.0; Thermo-Fisher Scientific, Waltham, MA). Triplicate analysis was performed on each sample. The quantitative analysis was performed by comparing the area of chromatographic peak of each compound with that of in the IS added in a known amount to the sample before analysis. The final data are expressed as nanograms of internal standard equivalent area.

\section{GC-MS Determination of Phthalates in Milk}

High-purity phthalates $(>98.7 \%)$ were used as standards. The phthalates dimethyl phthalate (DMP), di-n-butyl phthalate (DnBP), benzyl butyl phthalate (BBP), di-2-ethylhexyl phthalate (DEHP), and di- $n$ oktyl phthalate (DnOP) were obtained from SigmaAldrich (St. Louis, MO). Dibutyl adipate (DBA), which was used as the IS, was purchased from Fluka (Sigma-Aldrich). All sample containers, flasks, centrifuge tubes, pipettes, et cetera coming in contact with samples, standards, and solvents were made of glass. Stock solutions $(100 \mu \mathrm{g} / \mathrm{mL})$ of DMP, DnBP, BBP, DEHP, and DnOP were prepared in hexane. Calibration standards containing $0.5,1,2.5$, and $5 \mu \mathrm{g} / \mathrm{mL}$ of each phthalate and $1 \mu \mathrm{g} / \mathrm{mL}$ of DBA were prepared daily in hexane from stock solutions. The stock and 
standard solutions were stored in the dark at $4^{\circ} \mathrm{C}$. A volume of $30 \mathrm{~mL}$ of milk with IS mixture added was mixed with $5 \mathrm{~mL}$ of methanol. Then, $20 \mathrm{~mL}$ of hexane and $5 \mathrm{~mL}$ of tert-butyl methyl ether were added and the mixture was shaken vigorously for $1 \mathrm{~min}$. The mixture was centrifuged at $1,500 \times g$ for $5 \mathrm{~min}$. The hexane-ether phase was transferred to another tube and extraction was repeated with $20 \mathrm{~mL}$ of hexane and $5 \mathrm{~mL}$ of tert-butyl methyl ether. The combined extract was evaporated to dryness at $70^{\circ} \mathrm{C}$ under a nitrogen flow and the residue was redissolved in 3.0 $\mathrm{mL}$ of hexane. Blanks were prepared in the same way using prescreened water instead of milk sample. For clean-up, sample extract was shaken with $3.0 \mathrm{~mL}$ of acetonitrile for $1 \mathrm{~min}$. The hexane phase was discarded and extraction was repeated with $1.0 \mathrm{~mL}$ of hexane. The hexane phase was removed and discarded. The acetonitrile phase was evaporated to dryness at $70^{\circ} \mathrm{C}$ under nitrogen. The residue was redissolved in $500 \mu \mathrm{L}$ of acetonitrile.

A Hewlett Packard 6890 gas chromatograph (Hewlett Packard, Palo Alto, CA) equipped with an Agilent 5973 mass-selective detector (Agilent, Santa Clara, CA) was used, and the column was DB-5MS 5\% phenyl methyl siloxane-coated capillary column $(30 \mathrm{~m} \times 0.25$-mm i.d., $0.25-\mu \mathrm{m}$ film thickness; Agilent Technologies, J\&W Scientific, Folsom, CA). The oven was programmed from $60^{\circ} \mathrm{C}$ for $3 \mathrm{~min}$ to $290^{\circ} \mathrm{C}$ for $10 \mathrm{~min}$, at a rate of $10^{\circ} \mathrm{C} / \mathrm{min}$. The gas chromatograph was operated in splitless injection mode at a temperature of $290^{\circ} \mathrm{C}$. The operating temperature of the mass-selective detector was $280^{\circ} \mathrm{C}$ with electron impact at $70 \mathrm{eV}$. The mass-selective detector was used in the ion-monitoring (SIM) mode at $m / z 149,163$, and 279 . The dwell time was $100 \mathrm{~ms}$. Identification of target compounds was based on the relative retention time, the presence of target ions, and their relative abundance. Ions used for quantification were $\mathrm{m} / z 163$ (DMP), 149 (DnBP, BBP, DEHP), and 279 (DnOP). The concentrations of phthalate esters were calculated from calibration curves that were constructed by adding known amounts of the phthalate esters to a milk sample in the final concentration range from 0 to $10 \mu \mathrm{g} / \mathrm{L}$ (5 points). High coefficients of determination $\left(\mathrm{R}^{2}>0.997\right)$ were obtained for all phthalate esters.

\section{Animal Experiment}

Adult male albino Wistar rats, 6 wk old, weighing $220 \pm 15$ g, were purchased for the experiment. Rats were housed in polypropylene cages in a room in which the temperature was $25 \pm 1^{\circ} \mathrm{C}$ and 12 -h light and dark cycles were maintained. Before the experiment, all animals were on standard laboratory chow diet, which contained 20\% protein (purchased from Veterinary Institute, Subotica, Serbia). The standard laboratory chow food was given in daily dose of $20 \mathrm{~g}$ per rat, meaning that each rat received $4 \mathrm{~g}$ of protein daily. Experimental groups that received untreated or DP milk instead of standard laboratory chow received milk in a daily dose adjusted to a total protein level equal to that of the standard laboratory chow diet (135 g of milk per rat per $24 \mathrm{~h}$ was equivalent to $4 \mathrm{~g}$ of protein per rat per $24 \mathrm{~h}$ ). Experimental hyperuricemia in rats was induced by an uricase inhibitor, potassium oxonate, dissolved in drinking water, in daily dose of $100 \mathrm{mg}$.

Oxonic acid was purchased from Sigma-Aldrich and allopurinol was purchased from Zorka Pharma (Šabac, Serbia). The rats were randomly divided into 8 experimental groups (7 rats per each group) with different dietary regimens for 10 d. Experimental groups were designated as follows: (1) control group on standard laboratory chow; (2) oxonate (oxonic acid)-treated group (experimental hyperuricemia) on standard laboratory chow; (3) oxonate-treated group + allopurinol (given in a daily dose of $20 \mathrm{mg}$ dissolved in drinking water); (4) oxonate-treated group fed only DP milk; (5) oxonate-treated group fed only commercial (untreated) milk; (6) DP milk only in a quantity equal to that of group 4; (7) untreated milk only in a quantity equal to that of group 5; and (8) allopurinol only in a daily dose of $20 \mathrm{mg}$ (equal to that of group 3 ). All animals received water ad libitum.

\section{Isolation of Rat Blood and Liver Tissue}

Experimental procedures used in this study met the Guide for the Care and Use of Laboratory Animals of the Medical Faculty (Niš, Serbia; www.medfak.ni.ac.rs). Animals were killed under ketamine anesthesia after 10 $\mathrm{d}$, and blood was collected from the abdominal aorta after opening the peritoneal cavity. Plasma was isolated after centrifugation of blood. The left lobe of the liver was removed quickly and rinsed in physiological saline, and then it was homogenized by using a tissue homogenizer. The samples were kept at $-20^{\circ} \mathrm{C}$ before analysis.

\section{UA Analyses and Determination of Protein Kinases in Rat Liver}

Plasma Analyses. Analysis of uric acid in plasma was performed by using Dade Behring RxL Max automatic analyzer (Dade Behring-Siemens, Glasgow, UK). The method is based on spectrophotometric measurement by uricase-peroxidase method using a standard International Federation of Clinical Chemistry protocol.

Analyses of Liver Signaling Proteins. An ELISA method was standardized in our laboratory according 
to the previous protocol developed by Nix and Wild (2000) and the liver analyses were performed in the following steps. First, liver proteins were immobilized on solid polystyrene microtiter plates by pipetting $10 \mu \mathrm{L}$ of each liver protein sample into flat-bottomed, 96-well plates, using 2 plates for each antigen (serving as the test and control plates). The antigens presented in liver were directly attached to the plate by adsorption using $90 \mu \mathrm{L}$ of carbonate-bicarbonate coating buffer $(100$ $\mathrm{m} M, \mathrm{pH} 9.6$ ) and incubated at $4^{\circ} \mathrm{C}$ overnight.

Antigen detection was performed by incubating each test plate with the corresponding primary antibody for the next $24 \mathrm{~h}$ at $4^{\circ} \mathrm{C}$. The following antibodies were purchased from Santa Cruz Biotechnol-

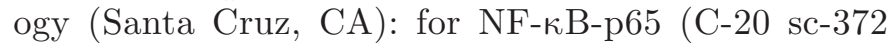
epitope mapping at the $\mathrm{C}$-terminus of $\mathrm{NF} \kappa \mathrm{B}$, mouse monoclonal $\operatorname{IgG}_{1}$ ), for Akt1 (5C10: sc-81434, mouse monoclonal $\operatorname{IgG}_{1}$ ), for phosphorylated (p)-Akt1 (11E6: sc-81433, mouse monoclonal $\operatorname{IgG}_{1}$ ), for ERK 1/2 (MK1: sc-135900, mouse monoclonal $\operatorname{IgG}_{1}$ ), for p-ERK 1/2 (pT202/pY204.22A: sc-136521, mouse monoclonal $\mathrm{IgG}_{1}$ ), for IRAK-1 (F-4: sc-5288, mouse monoclonal $\mathrm{IgG}_{1}$ ), for p-IRAK-1 (Ser376: sc-130197, rabbit monoclonal $\operatorname{IgG}_{1}$ ), for p38 (27: sc-136210, mouse monoclonal $\operatorname{IgG}_{1}$ ), and for p-p38 (D-8: sc-7973, mouse monoclonal $\mathrm{IgG}_{1}$ ).

For the secondary antibody assay, the plates were washed 3 times with PBS and then both test and control plates were incubated with corresponding fluorescein isothiocyanate (FITC)-conjugated secondary antibody (sc-7972 FITC) anti-mouse or anti-rabbit, as needed, for $2 \mathrm{~h}$ in the dark. The excess of antibody following staining was washed again 3 times with PBS.

Fluorescence measurement was performed on a Victor Perkin Elmer-Wallac multiplate reader (Perkin-Elmer, Waltham, MA). The mean fluorescence intensity (logarithmic scale) was determined such that control plate values, where primary antibody was omitted, were subtracted from test plate values. The actual amount of active transcriptional factors and enzymes was expressed per milligram of cellular protein.

\section{Liver DNase Determination}

The activity of alkaline DNase was measured by the method of Bartholeyns et al. (1975), in which acidsoluble nucleotides, released after DNA degradation, are determined spectrophotometrically at $260 \mathrm{~nm}$. The enzyme activity was expressed in units per gram of protein. The increase in absorbance of $0.001 / \mathrm{min}$ in a sample containing $0.132 \mathrm{mg}$ of DNA at $\mathrm{pH} 7.4$, by using a standard commercial DNase I obtained from Sigma Aldrich was used as the unit for purified DNase I.

\section{Statistical Analyses}

All data were expressed as mean \pm standard deviation. Comparison between the dietary groups for each parameter analyzed was performed using ANOVA. Differences were considered statistically significant at $P<$ 0.05. Multivariate statistical analysis was performed by using principal component analysis (PCA) to extract the most discriminating variables in a data set consisting of 11 measured parameters (plasma UA and liver parameters: NFkB-p65, Akt kinase, p-Akt kinase, ERK kinase, p-ERK kinase, IRAK kinase, p-IRAK kinase, p38, p-p38, and DNase) for 8 experimental groups of animals.

\section{RESULTS}

\section{UA Analyses}

Uric acid was the main purine compound in the untreated UHT milk, due to homogenization and subsequent liberation of xanthine oxidase, which degraded the presented purines. Figure 1 represents HPLC-DAD chromatograms obtained for untreated commercial and DP milk samples prepared using our patented procedure. This procedure significantly lowered the amount of not only UA (the main purine compound) but also orotic acid (the main pyrimidine compound in commercial milk) in DP milk.

\section{Experimental Hyperuricemia in Rats Following Allopurinol Therapy or Milk Diet}

The results of experimentally induced hyperuricemia by oxonic acid and the effects of allopurinol and 2 types of milk dietary regimen on plasma UA and liver NFkB-p65, Akt kinase/p-Akt kinase, ERK/pERK, IRAK/p-IRAK, p38/p-p38 protein expression, and DNase activity are shown in Figures 2 through 8. Mean plasma UA level of rats given oxonate indicated that they developed hyperuricemia, because oxonic acid induced a 2-fold increase in plasma UA, whereas allopurinol had a significant hypouricemic effect. Depurinized milk slightly potentiated hyperuricemia, whereas untreated commercial milk significantly potentiated hyperuricemia. Given alone as a 10-d diet, DP milk induced only negligible increase of UA, whereas untreated milk induced a significant increase in UA compared with control UA level, when rats were on a commercial vegetarian laboratory chow regimen. Allopurinol had no significant effect on UA when given alone to control rats fed a standard diet (Figure 2). The assessed level of active NF- $\kappa$ B-p65 subunit was significantly decreased during oxonic acid treatment, whereas 


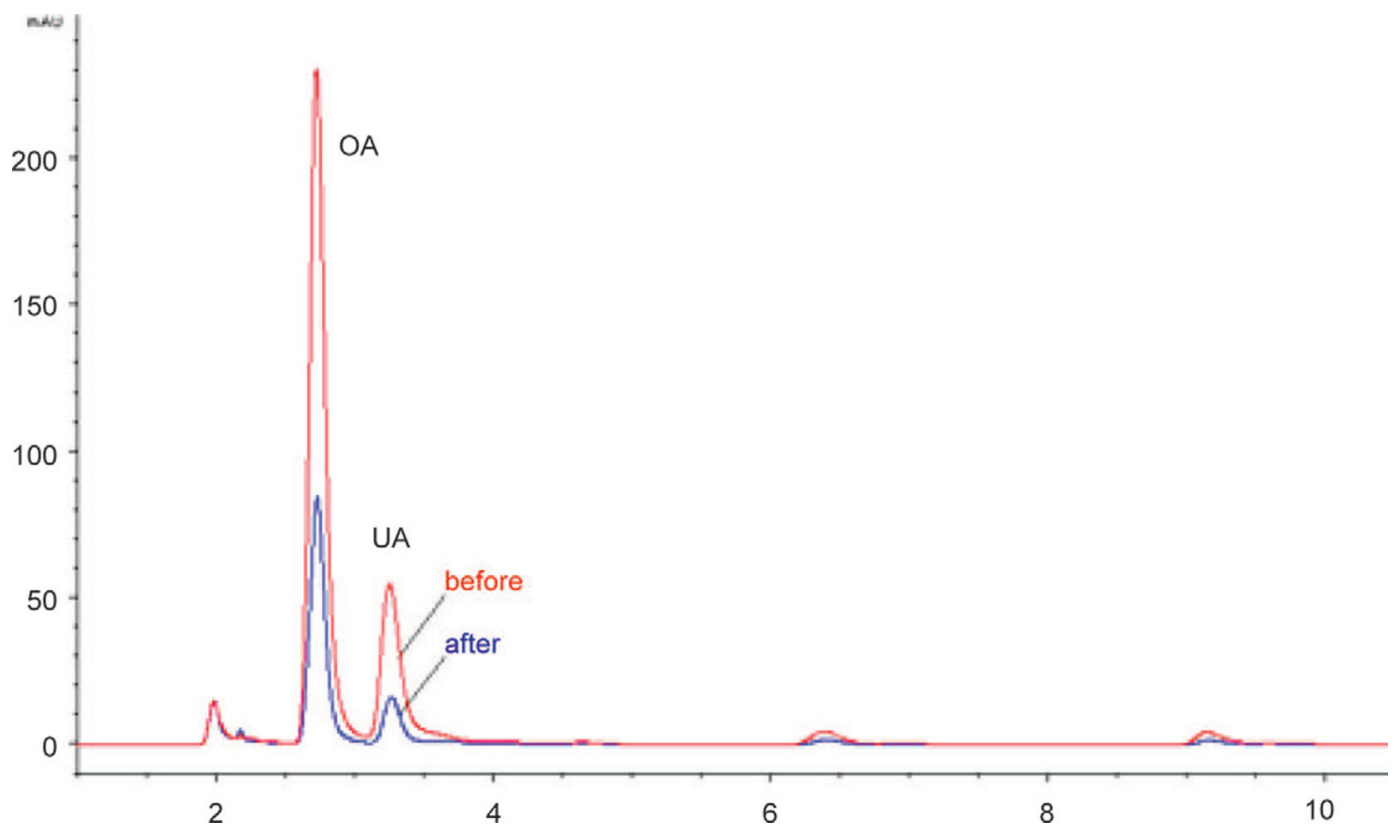

Figure 1. High performance liquid chromatography determination of uric and orotic acids in milk before and after process of depurinization. Purine (uric acid, UA) and pyrimidine (orotic acid, OA) compound classes in milk specimens were determined using HPLC-diode-array detection (DAD) system. Color version available in the online PDF.

milk dietary regimens significantly increased active

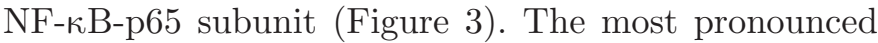
effect was documented for commercial untreated milk given to hyperuricemic or control rats. Oxonic acid had almost no effect on Akt-kinase/p-Akt kinase, whereas the DP milk dietary regimen given in hyperuricemic conditions induced a 20-fold increase in the active pAkt kinase form and a more than 2-fold increase in the inactive (Akt) form. In control rats, the DP milk diet increased the p-Akt kinase form about 10-fold. Untreated commercial milk was about 4 times less potent than depurinized milk when given to hyperuricemic or control rats (Figure 4). Consistent with previous results, active p-ERK showed an almost 10-fold increase in rats fed on DP milk, whereas its inactive (ERK) form increased about 3-fold. Untreated milk was able to induce ERK, but not p-ERK, to the same extent. Interestingly, neither hyperuricemia nor allopurinoltreated hyperuricemia changed ERK or p-ERK in liver tissue (Figure 5). The same trend was observed for IRAK/p-IRAK but to a lesser extent (Figure 6). Because the milk diet regimen was initially identified as a possible stimulator of liver cell regenerative potential, the aim of our further research was to explore possible pro-apoptotic proteins and enzyme DNase. Because ERK and p38 usually express opposite effects, it was not surprising that DP milk and commercial untreated milk significantly decreased p-p38 level compared with that in control rats. No other experimental regimen sig- nificantly altered p38 or p-p38 (Figure 7). Furthermore, the activity of DNase I responsible for nuclear DNA fragmentation was significantly decreased in rats fed the DP milk regimen, and allopurinol exerted a similar effect (Figure 8).

Table 1 shows GC-MS data for the analysis of volatile organic compounds in milk samples investigated in this study. A total of 24 volatile organic compounds (sulfur compounds, ketones, aldehydes, alcohols, esters, and carboxylic acids) were detected and quantified in the commercial milk sample, 6 of which were not detectable in DP milk. For the rest of compounds, mostly significant decreases in concentration were observed in DP milk compared with untreated milk. Table 2 shows the results of the concentration measurements for the investigated phthalate esters. The decrease in the level of individual phthalates and total phthalate concentration after milk depurinization was evident and statistically significant.

The PCA of uric acid and liver parameters data for 8 experimental groups of animals revealed that 2 principal components (PC) explained $97 \%$ of total variance in this data set (PC1: $87 \%$, and PC2: 10\%) as shown in Figure 9. Figure 10 shows that the highest values of loadings on PC1 had p-Akt and p-ERK, whereas highest values of loadings on PC2 had ERK and p-ERK. Other parameters investigated in this study had much smaller loadings on both PC1 and PC2. This means that these 3 parameters (p-Akt, ERK, and p-ERK) are 


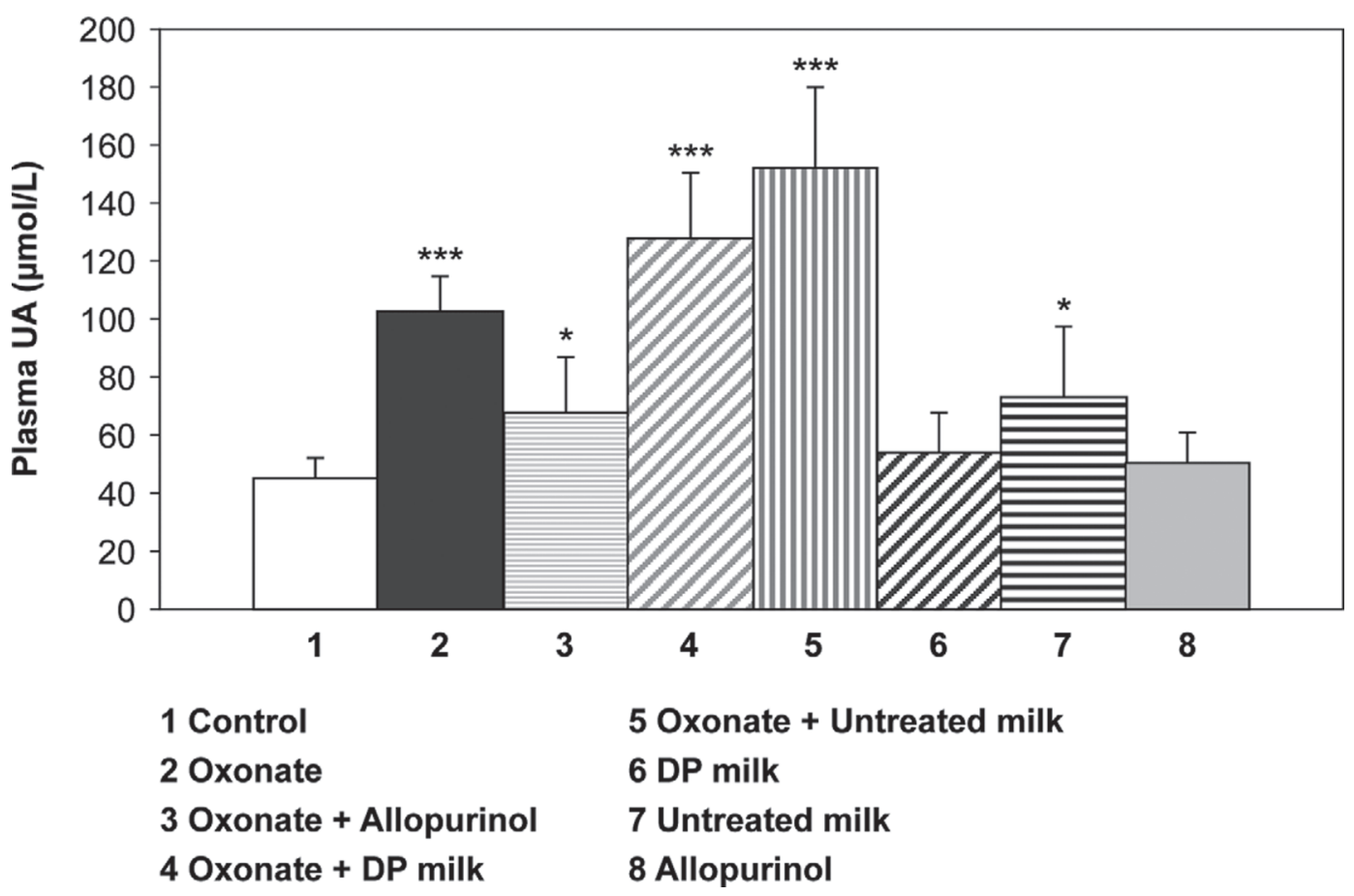

Figure 2. Plasma uric acid (UA) concentration in investigated groups. Measurement of plasma UA concentration was performed by using Dade Behring RxL Max automatic analyzer (Dade Behring-Siemens, Glasgow, UK). Values are given as means $\pm \mathrm{SD} ;{ }^{*} P<0.05 ;{ }^{* * *} P<0.001$ vs. control. DP = depurinized.

the most discriminating variables in this data set and most useful for explaining the results of this study.

\section{DISCUSSION}

Our experimental study indicated that a milk dietary regimen with our newly patented DP milk diet, compared with untreated, commercial UHT cow milk or allopurinol therapy, was able to exert a hepatoprotective effect on experimental hyperuricemia induced by oxonic acid and on healthy liver tissue, independent of the influence on UA level. The reduction or elimination of many potentially toxic volatile organic compounds by the patented depurinization procedure may explain the beneficial effect of DP milk on liver regenerative potential, because hyperuricemia per se did not induce a marked decrease of liver regenerative potential, as was hypothesized previously. The present study suggested that milk dietary regimens, compared with standard laboratory chow (vegetarian diet), may have a significant influence on liver signaling pathways important for regulation of cell survival and apoptosis. This was documented in relation to liver growth-regulatory signaling enzymes (Akt/p-Akt kinase, ERK/p-ERK kinase, IRAK/p-IRAK kinase) and transcriptional factor NF- $\kappa \mathrm{B}$ p65 active subunit. Wistar rats proved to be appropriate animals for examining the nutrigenomic metabolic changes associated with nutritional habits, including milk consumption, because they typically live on a vegetarian chow diet. We found a substantial increase in the total expression of intact and activatedphosphorylated forms of Akt-1, ERK, and IRAK in livers of rats fed the DP milk diet. This effect was significantly more expressed for DP milk than for commercial milk, whereas an increase in NF- $\kappa$ B p65 subunit was expressed to a lesser extent for DP milk than for commercial untreated milk.

In this study, we did not observe a significant effect of hyperuricemic conditions on liver regenerative potential investigated through the Akt-kinase-ERKIRAK kinase pathway. However, the results obtained after the treatment of hyperuricemic or intact rats with DP milk, indicated that DP milk may exert a beneficial effect, most probably independent of UA. Regarding milk, evidence suggests that mitogenic growth factors and insulin-like growth factors, usually present in milk, can survive digestion and can remain bioactive in milk consumers. That is why milk consumption in humans may be associated with about a 20 to $30 \%$ increase in circulating IGF-1 and insulin levels, as documented by Ljijeberg Elmståhl and Bjorck (2001). In evaluating the central role of MAP kinases and Akt kinase in metabolism, Whiteman et al. (2002) documented that IGF-1 can exert a strong mitogenic and cell prolifera- 


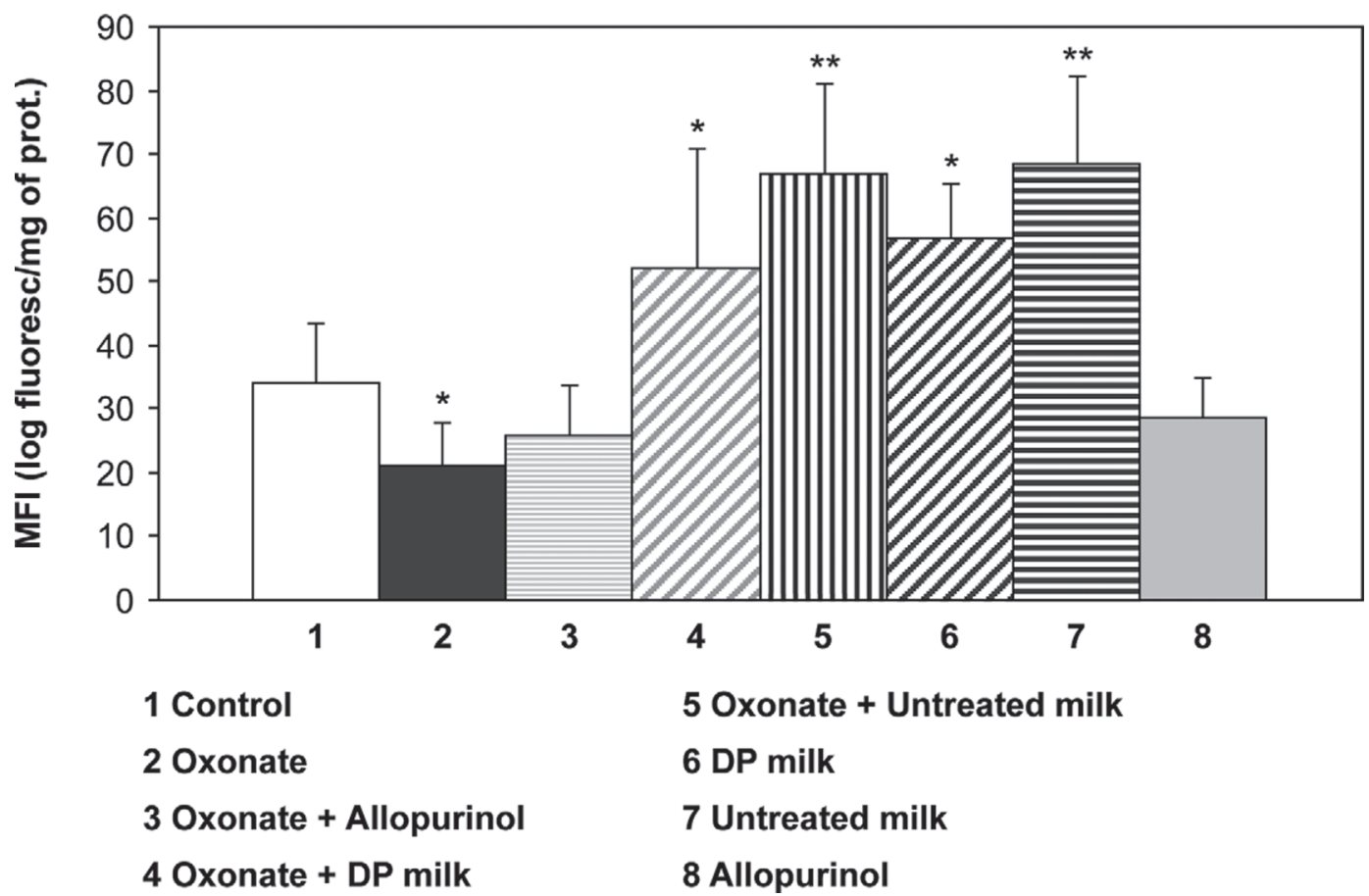

Figure 3. Liver nuclear factor $\kappa \mathrm{B}(\mathrm{NF}-\kappa \mathrm{B}) \mathrm{p} 65$ subunit in investigated groups. The ELISA assay was performed by using primary antibody

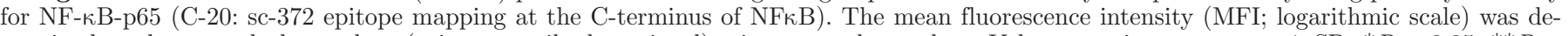
termined as the control plate values (primary antibody omitted) minus test plate values. Values are given as means $\pm \mathrm{SD} ;{ }^{*} P<0.05 ;{ }^{* *} P<$ 0.01 vs. control. $\mathrm{DP}=$ depurinized.

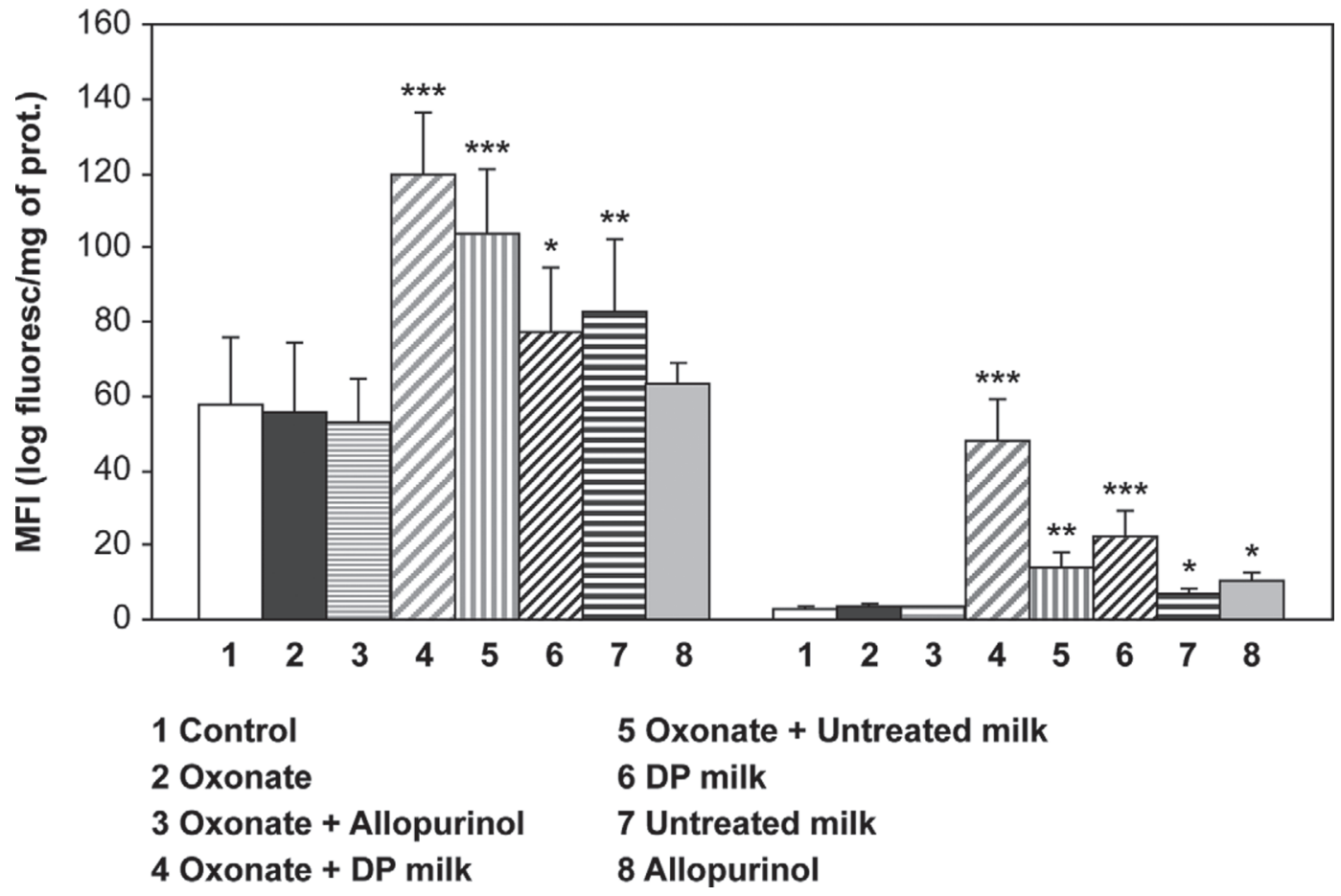

Figure 4. Liver Akt kinase/phosphorylated (phospho)-Akt kinase in investigated groups. The ELISA assay was performed by using primary antibody for Akt1 (5C10: sc-81434) mouse monoclonal IgG and for p-Akt1 (11E6: sc-81433). The mean fluorescence intensity (MFI; logarithmic scale) was determined as the control plate values (primary antibody omitted) minus test plate values. Values are given as means $\pm \mathrm{SD} ; * P<$ $0.05 ;{ }^{* *} P<0.01 ; * * *<0.001$ vs. control. $\mathrm{DP}=$ depurinized. 


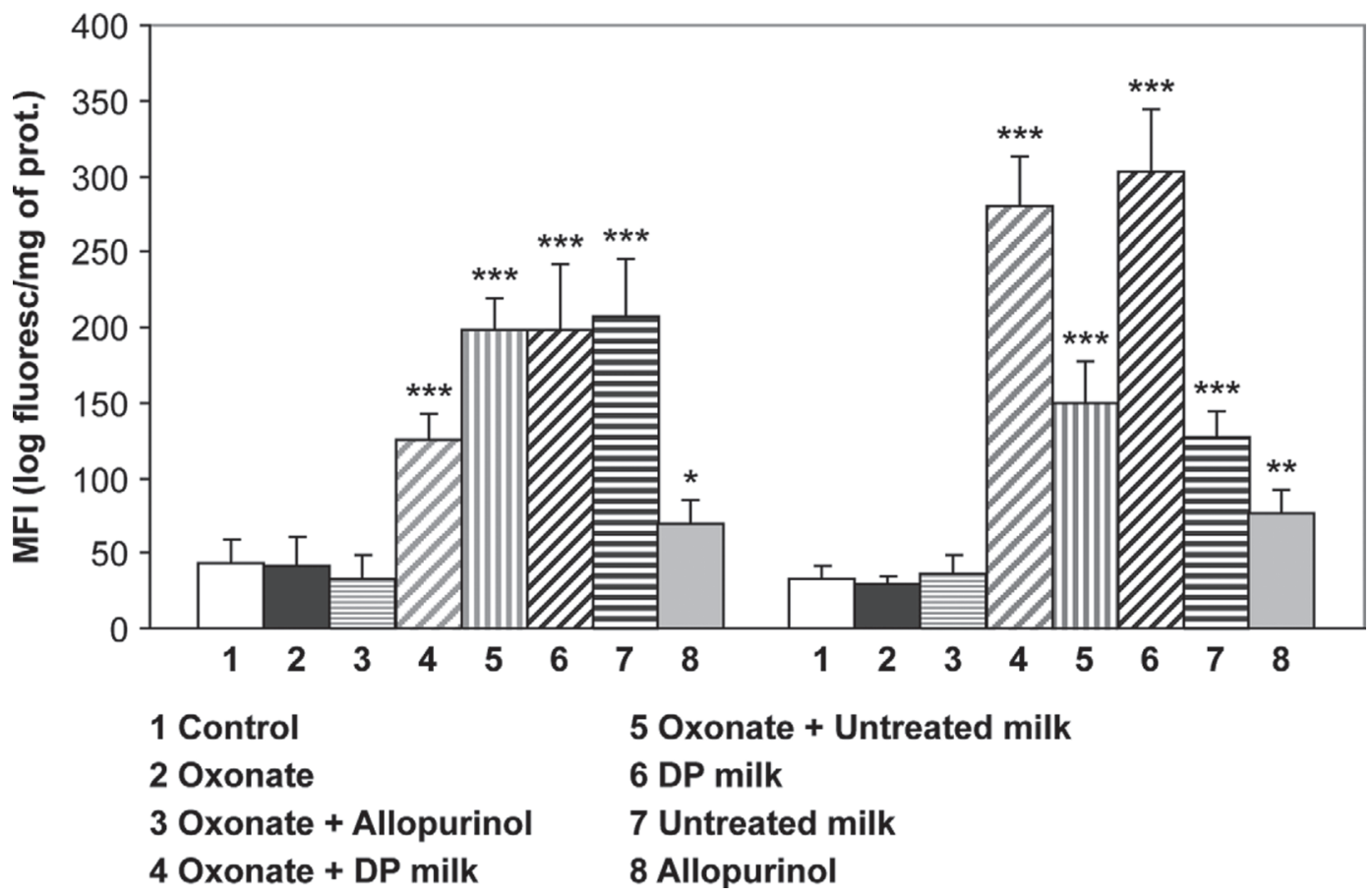

Figure 5. Liver extracellular signal-regulated kinase (ERK)/phosphorylated (phospho)-ERK in investigated groups ELISA assay was per-

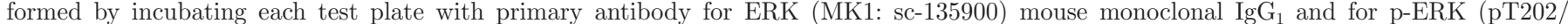
pY204.22A: sc-136521) mouse monoclonal $\mathrm{IgG}_{1}$. The mean fluorescence intensity (MFI; logarithmic scale) was determined as the control plate values (primary antibody omitted) minus test plate values. Values are given as means $\pm \mathrm{SD} ;{ }^{*} P<0.05 ;{ }^{* *} P<0.01 ; * * * P<0.001$ vs. control. $\mathrm{DP}=$ depurinized.

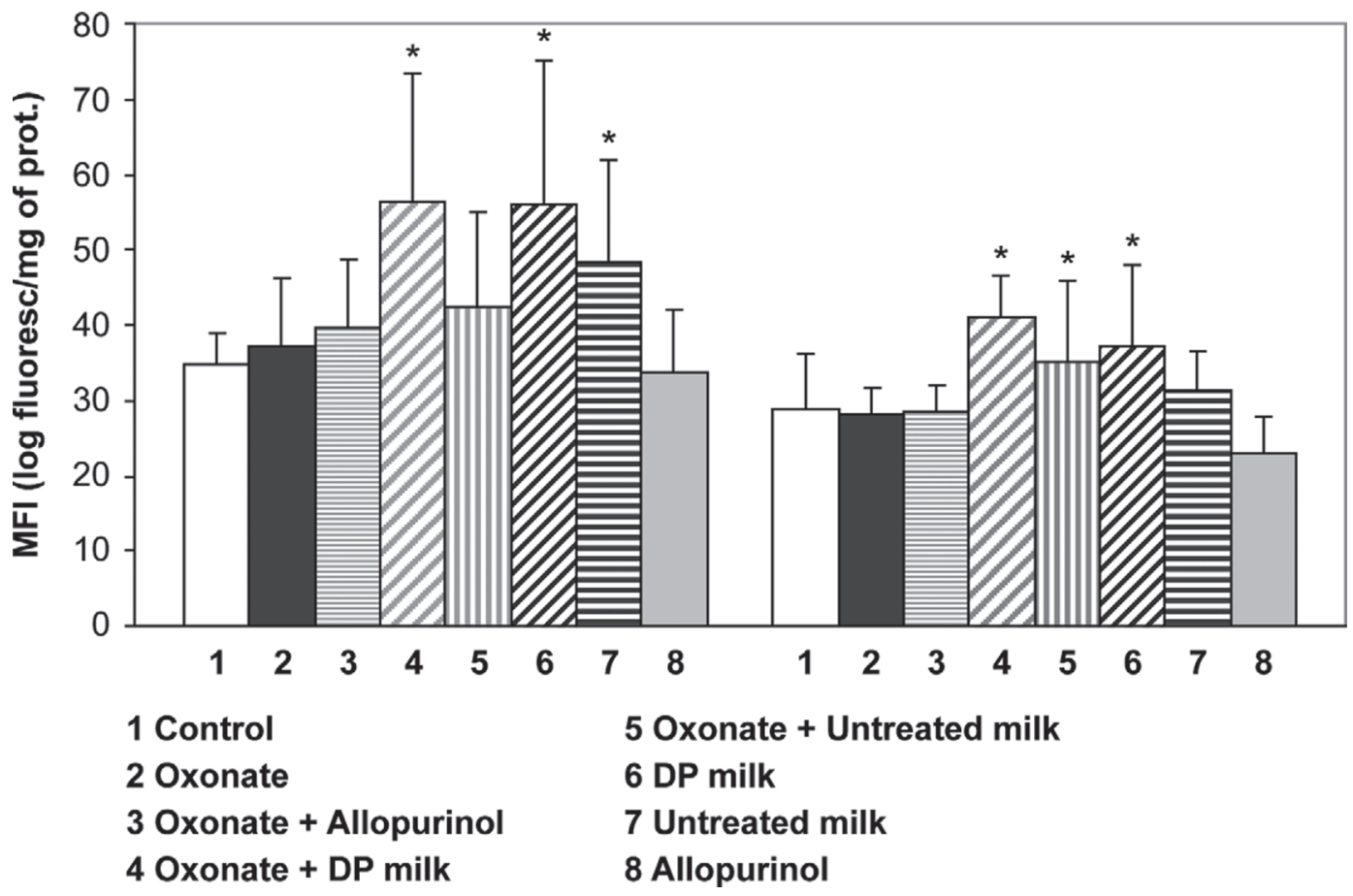

Figure 6. Liver IL-1 receptor-associated kinase (IRAK)/phosphorylated (phospho)-IRAK in investigated groups ELISA assay was performed by incubating each test plate with primary antibody for IRAK-1 (F-4: sc-5288) mouse monoclonal IgG 1 and for p-IRAK-1 (Ser376: sc-130197). The mean fluorescence intensity (MFI; logarithmic scale) was determined as the control plate values (primary antibody omitted) minus test plate values. Values are given as means $\pm \mathrm{SD} ;{ }^{*} P<0.05$ vs. control. DP $=$ depurinized. 


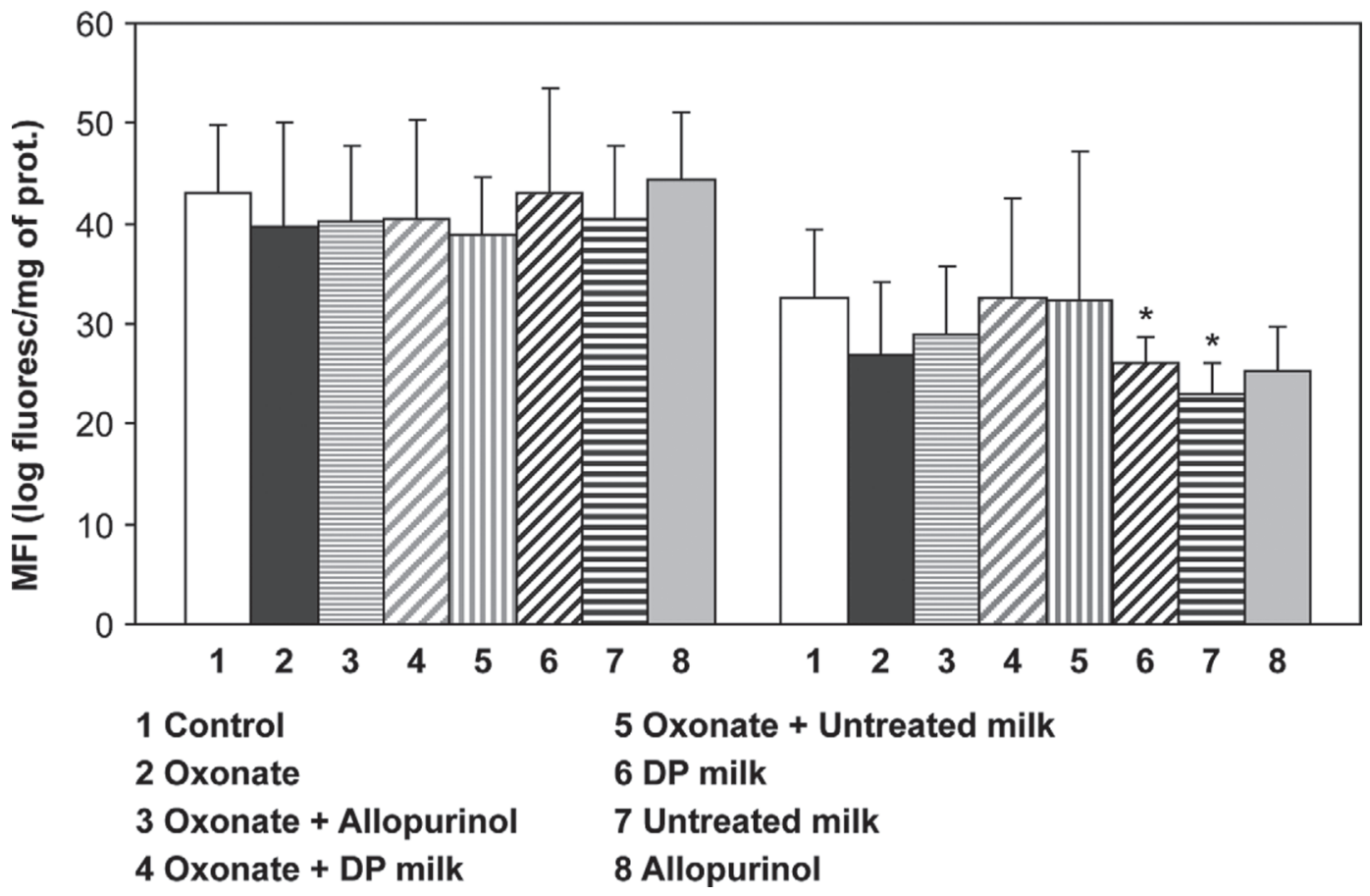

Figure 7. Liver p38 mitogen-activated protein (MAP) kinase/phosphorylated (phospho)-p38 in investigated groups. The ELISA assay was performed by using primary antibody for p38 (27: sc-136210) mouse monoclonal IgG $_{1}$, for p-p38 (D-8: sc-7973). The mean fluorescence intensity (MFI; logarithmic scale) was determined as the control plate values (primary antibody omitted) minus test plate values. Values are given as means $\pm \mathrm{SD} ;{ }^{*} P<0.05$ vs. control. $\mathrm{DP}=$ depurinized.

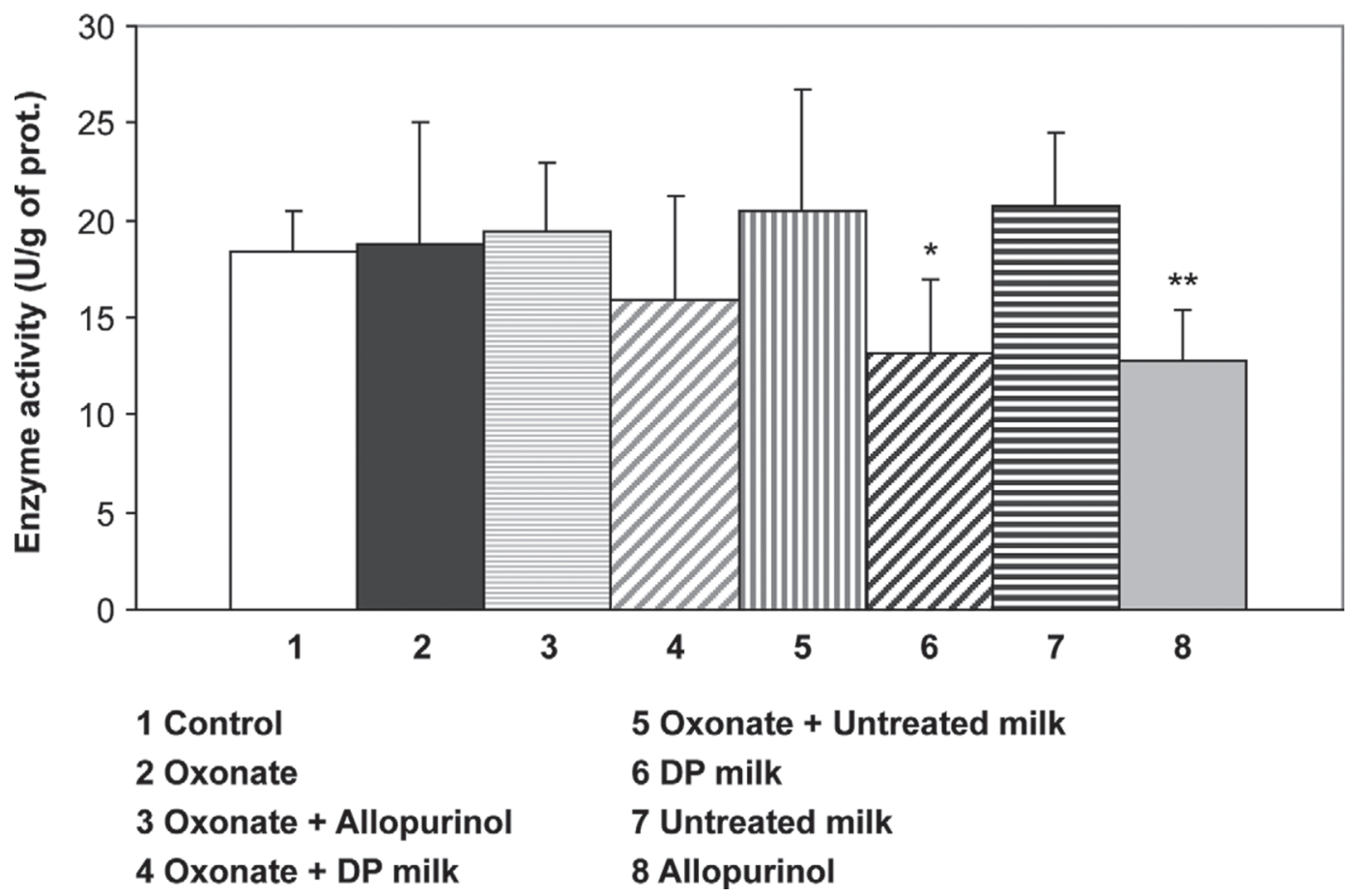

Figure 8. Liver DNase in investigated groups. The activity of alkaline DNase was monitored by the methods of Bartholeyns et al. (1975), where acid-soluble nucleotides, released after DNA degradation, were determined spectrophotometrically at $260 \mathrm{~nm}$. Enzyme activity was expressed in units per gram of protein. Values are given as means $\pm \mathrm{SD} ;{ }^{*} P<0.05 ;{ }^{*} P<0.01$ vs. control. DP $=$ depurinized. 
Table 1. Profile of volatile compounds in untreated commercial and depurinized milk samples ${ }^{1}$

\begin{tabular}{|c|c|c|c|c|c|}
\hline \multirow[b]{2}{*}{ Compound } & \multicolumn{2}{|c|}{ Control milk } & \multicolumn{2}{|c|}{ Depurinized milk } & \multirow[b]{2}{*}{$P$-value } \\
\hline & Mean & $\mathrm{SD}$ & Mean & $\mathrm{SD}$ & \\
\hline \multicolumn{6}{|l|}{ Sulfur compounds } \\
\hline Dimethylsulfide & $2,577.86$ & 286.61 & 65.09 & 38.48 & $*$ \\
\hline Dimethylsulfoxide & 93.19 & 17.82 & 12.33 & 2.09 & $*$ \\
\hline Dimethylsulfone & 17.88 & 8.07 & 10.51 & 5.97 & NS \\
\hline Total & $2,688.93$ & & 87.93 & & $*$ \\
\hline \multicolumn{6}{|l|}{ Ketones } \\
\hline Propanone (acetone) & 400.44 & 48.47 & 98.60 & 31.66 & $*$ \\
\hline Butanone & 41.68 & 1.34 & 7.74 & 5.20 & * \\
\hline 2-Pentanone & 58.78 & 12.45 & 491.83 & 90.93 & * \\
\hline 3-Methyl-2-butanone & 2.45 & 0.15 & 3.04 & 0.79 & NS \\
\hline 2-Heptanone & 222.16 & 32.30 & 43.12 & 12.61 & $*$ \\
\hline 3-Hydroxy-2-butanone & 34.22 & 7.03 & 1.90 & 0.41 & $*$ \\
\hline 2-Octanone & 3.06 & 0.28 & $\mathrm{ND}^{2}$ & - & $*$ \\
\hline 2-Nonanone & 26.67 & 4.81 & 9.82 & 1.45 & $*$ \\
\hline 2-Undecanone & 3.48 & 0.58 & 4.69 & 2.01 & NS \\
\hline Total & 792.94 & & 660.74 & & $*$ \\
\hline \multicolumn{6}{|l|}{ Aldehydes } \\
\hline Nonanal & 4.18 & 0.84 & 0.61 & 0.26 & $*$ \\
\hline Total & 4.18 & & 0.61 & & * \\
\hline \multicolumn{6}{|l|}{ Alcohols } \\
\hline Ethanol & 624.36 & 57.30 & 38.11 & 12.43 & * \\
\hline 3-Methyl-1-butanol & 12.94 & 2.13 & 35.83 & 6.94 & $*$ \\
\hline 1-Pentanol & 5.43 & 1.29 & 5.18 & 0.70 & NS \\
\hline 1-Hexanol & 3.76 & 0.23 & 2.73 & 0.62 & $*$ \\
\hline Total & 646.49 & & 81.85 & & * \\
\hline \multicolumn{6}{|l|}{ Esters } \\
\hline Hexanoic acid ethyl ester & 9.82 & 0.03 & ND & - & * \\
\hline Octanoic acid ethyl ester & 0.87 & 0.16 & ND & - & $*$ \\
\hline Total & 10.69 & & ND & - & \\
\hline \multicolumn{6}{|l|}{ Carboxylic acids } \\
\hline Acetic acid & 17.53 & 8.94 & 3.83 & 0.87 & * \\
\hline Pivalic acid & 5.02 & 2.68 & ND & - & * \\
\hline Butanoic acid & 3.15 & 0.58 & 1.13 & 0.07 & * \\
\hline Pentanoic acid & 3.74 & 0.14 & ND & - & * \\
\hline Hexanoic acid & 13.54 & 1.95 & 1.70 & 0.82 & $*$ \\
\hline Total & 42.98 & & 6.66 & & $*$ \\
\hline
\end{tabular}

${ }^{1}$ Each value represents the average of a triplicate measurement; data are expressed as nanograms of internal standard equivalent area.

${ }^{2}$ Not detected.

$* P<0.001$.

tion effect, mediated by the activation of the Ras-RafMAP kinase and phosphoinositide 3-kinase (PI3K)-Akt pathway. By studying the mechanisms of Akt kinase activation, Jackson et al. (2008), Hers et al. (2011), and Fujiyoshi and Ozaki (2011) documented that Akt kinase becomes active by phosphorylation at Thr308 and Ser473 sites, via PI3K, and exerts a potent phosphorylating activity to more than 50 different cellular proteins, thus having a central role in cell survival and regulation of cellular metabolism, including glucose utilization, insulin effects, cell cycle progression, proliferation, differentiation, and survival. The amount of ac-

Table 2. Concentrations of phthalates $(\mu \mathrm{g} / \mathrm{L})$ in commercial untreated (control) and depurinized milk samples

\begin{tabular}{lcccccc}
\hline & \multicolumn{2}{c}{ Control milk } & & \multicolumn{2}{c}{ Depurinized milk } \\
\cline { 2 - 3 } \cline { 6 - 7 } Phthalate & Mean & SD & & Mean & SD \\
\hline Di- $n$-butyl phthalate (DnBP) & 9.14 & 0.65 & & 1.62 & 0.23 \\
Benzyl butyl phthalate (BBP) & 1.35 & 0.01 & & ND $^{1}$ & \\
Bis(2-ethylhexyl) phthalate (DEHP) & 9.95 & 1.02 & & 4.14 & 0.68 \\
Di- $n$-octyl phthalate (DnOP) & 3.69 & 0.08 & & 1.20 & \\
Total phthalates & 24.13 & & & 6.96 & \\
${ }^{1}$ Not detected. & & & &
\end{tabular}




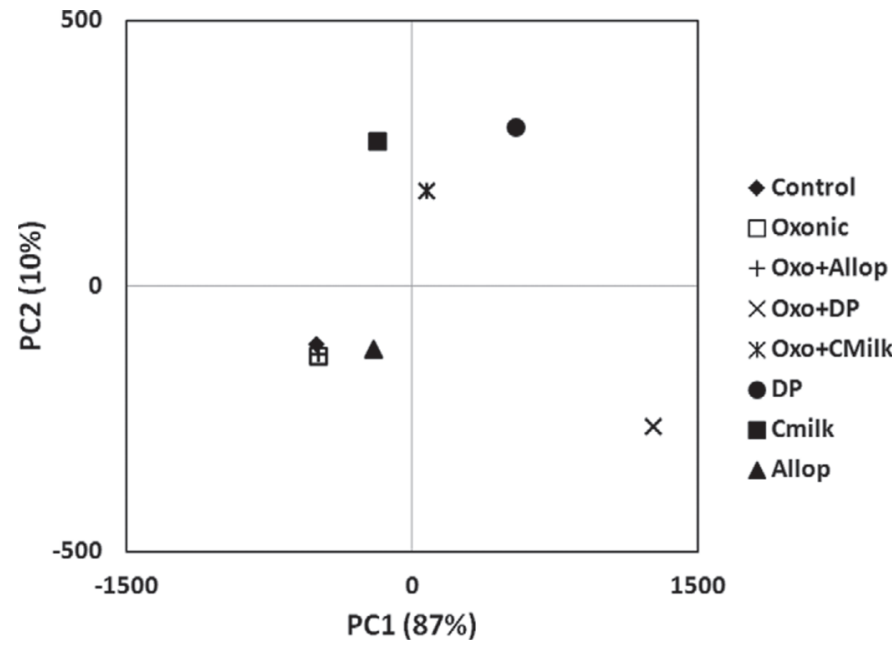

Figure 9. Multivariate statistical analysis by using principal component (PC) analysis for 8 experimental groups as tested variables to evaluate the possibility of calculating variables by using a correlation based on the maximum variance criterion. Control = standard laboratory chow; oxonic $=$ oxonic acid-treated group (experimental hyperuricemia) on standard laboratory chow; oxo+Allop = oxonic acid-treated group + allopurinol; oxo+DP $=$ oxonic acid-treated group fed only depurinized (DP) milk; oxo+CMilk = oxonic acid-treated group fed only commercial (untreated) milk; DP $=$ DP milk only; CMilk $=$ untreated milk only; and Allop = allopurinol in a daily dose of $20 \mathrm{mg}$.

tive, phosphorylated form of Akt kinase (p-Akt kinase) in cells is usually much lower than inactive (unphosphorylated) Akt kinase (Scheving et al., 2008), which was also observed in our study (Figure 4). Because Akt kinase plays a major role in activating compensatory recovery of liver mass following partial resection, our results may be consistent with increased liver regenerative potential. The Akt kinase may be responsible for the activation of NF- $\kappa \mathrm{B}$ in some inflammatory cells by acting as surviving signaling pathway.

Wada and Penninger (2004) proposed extracellular signal-regulated kinase (ERK1/2) to be the main player in the MAP kinase (MAPK) pathway. It is activated by phosphorylation of its Thr202/Tyr204 motifs, and activated ERK can phosphorylate about 150 downstream cell-signaling proteins, which are capable of regulating critical mechanisms in cell division, proliferation, survival, differentiation, and metabolism. Activation of ERK-1 can inhibit apoptosis induced by typical proapoptotic stimuli, such as tumor necrosis factor (TNF), Fas ligand, TNF-related apoptosisinducing ligand (TRAIL); exposure to radiation and oxidative stress; exposure to osmotic stress; hypoxia; growth factor withdrawal; or by some pharmacological agents, as studied by Lu and Xu (2006). Activated ERK kinases regulate a variety of transcription factors such as CREB and c-Myc, which are important in transcriptional activity, and 40S ribosomal protein

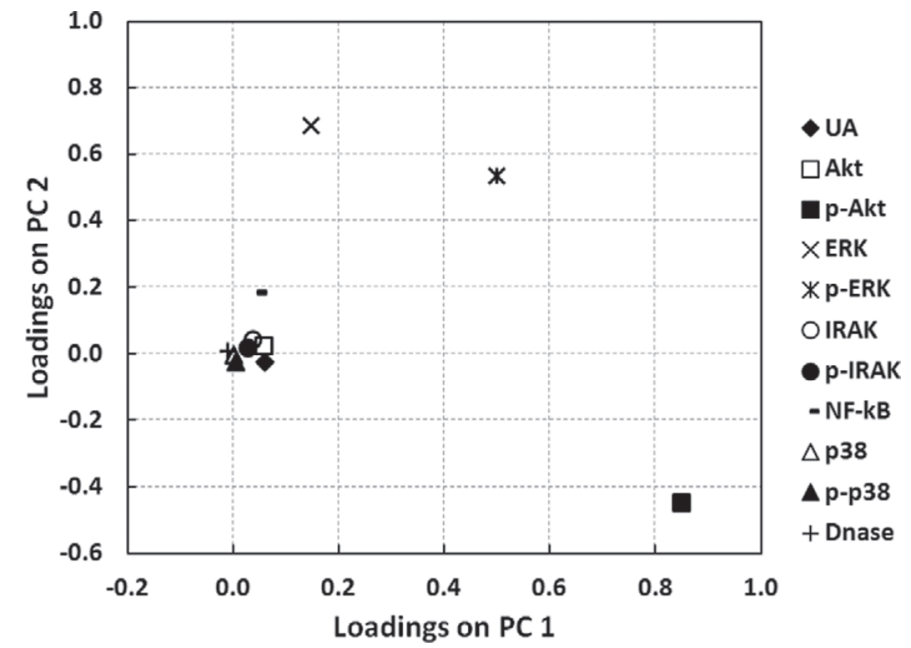

Figure 10. Multivariate statistical analysis by using principal component $(\mathrm{PC})$ analysis for 11 detected parameters as tested variables to evaluate the possibility of calculating variables by using a correlation based on the maximum variance criterion. $\mathrm{UA}=$ uric acid; Akt $=$ Akt kinase, $\mathrm{p}-\mathrm{Akt}=$ phosphorylated Akt kinase ERK $=$ extracellular signal-regulated kinase; p-ERK = phosphorylated ERK; IRAK = IL-1 receptor-associated kinase; p-IRAK = phosphorylated IRAK; NF-кB $=$ nuclear factor $\kappa \mathrm{B} ; \mathrm{p} 38=\mathrm{p} 38$ mitogen-activated protein (MAP) kinase; p-p38 = phosphorylated p38.

S6 kinase, which is important for translation of mRNA into protein, as documented in some cell cultures by Nätzker et al. (2002). Both milk dietary regimens in our study were able to exert significant effect in either hyperuricemic rats or healthy rats (Figure 5). Because ERK and the p38 cascade may have opposing effects on proliferation or apoptosis, results obtained for $\mathrm{p} 38$ and p-p38 were not surprising (Figure 7). As our results may suggest, experimental hyperuricemia induced by oxonic acid was not able to dramatically change the liver signaling responsible for cell proliferation or apoptosis, as far as Akt kinase, ERK, IRAK, and NF$\kappa \mathrm{B}$ were concerned. These results are consistent with our previous results showing the beneficial effect of the DP milk regimen on bone marrow stem cell potential, myocardial and metabolic stress parameters, advanced oxidation protein products, lipid peroxidation, plasma cholesterol, high-density lipoprotein cholesterol, and myocardial damage markers (creatine phosphokinase, aspartate transferase, , lactate dehydrogenase; unpublished results). In a recent study by Petta et al. (2011), it was found that the severity of liver steatosis and insulin resistance may be independently associated with lobular inflammation and hyperuricemia, which may be related to altered Akt kinase-regulated insulin signaling. It was documented by Ono et al. (2003) and Fujiyoshi and Ozaki (2011) that both ERK 1/2 and Akt kinases were important for liver regeneration and they were considered the key signaling molecules 
mediating the metabolic actions of insulin in liver. Ljijeberg Elmståhl and Bjorck (2001) noted that milk, as a supplement to mixed meals, may have a significant effect on postprandial insulinemia.

To analyze further the downstream antiapoptotic signaling, we monitored DNase activity. The dynamics of DNase activity may be in accordance with the obtained level of p38/p-p38 (Figure 8). Lu and Xu (2006) reported that programmed cell death, usually mediated through apoptosis, may be positively regulated by p38-MAP kinase activities and endonuclease activity. Degradation of the nuclear DNA usually occurs during epigenetic reprogramming in the $\mathrm{D}_{1}$ phase of programmed cell death, leading to double-stranded DNA fragmentation in the F phase. Several molecules involved in nuclear DNA fragmentation have been detected according to their $\mathrm{pH}$ ionic sensitivity. The presence of constitutive $\mathrm{Ca}^{2+}$ - and $\mathrm{Mg}^{2+}$-dependent endonucleases, with activity within the neutral-alkaline $\mathrm{pH}$ range, most probably represents the inducible form of DNase, caspase3-activated, known as DNase I or alkaline DNase. Enari et al. (1998) studied the mechanism of enzymatic catalysis of alkaline DNase and documented that alkaline DNase exerts the ability to degrade supercoiled, single-stranded, and double-stranded DNA. We found that DNase I activity was significantly decreased in groups treated with DP milk or allopurinol (Figure 8). Therefore, the proposed milk dietary regimen appeared to prevent apoptosis. In contrast, p38 and DNase activity may be stimulated by various cellular stress factors, such as inflammatory cytokines, oxidative stress, protein synthesis inhibitors, heating, toxic chemicals, or bacterial endotoxin (Nätzker et al., 2002).

A significant difference in the concentration of various potentially toxic compounds, such as sulfur compounds, aldehydes, ketones, carboxylic acids, or phthalates, was observed between commercial untreated and DP milk (Table 1 and Table 2). Some of the investigated compounds were not detected in DP milk. The experiments with toxic liver damage, performed by Hewitt et al. $(1983,1987)$, Chieli et al. (1990), and Tomei et al. (1999) documented that the severity of the hepatotoxic response was significantly (positively) correlated with the carbon chain length of given toxins. These observations suggest that carbon skeleton length may play a role in determining the toxic capacity of ketonic or other toxic compounds. Because phthalates are lipophilic, they may be present in fatty milk at high concentrations, especially when milk is in contact with materials containing phthalates as plasticizers, such as the polyvinyl chloride (PVC) milk tubing or PVC film for milk packaging. The phthalate levels in DP milk samples used in this study were generally low because our filter device system removes around $70 \%$ of phthalates from commercial milk for the production of DP milk. The reduction of phthalate contents after treatment is especially evident in the case of DnBP. The main removal mechanism is most likely sorption of phthalates on hydrophobic parts of sorbent due to their relatively nonpolar properties, as documented by Sørensen (2006).

\section{CONCLUSIONS}

This study attempted to clarify the nutrigenomic effect of milk dietary regimens (commercial and DP milk) and the pathogenetic link between hyperuricemia (or other potentially toxic volatile compounds present in milk) and liver regenerative potential. Our findings may give new insight into the role of milk dietary regimens in ameliorating liver function in normal and hyperuricemic conditions. Depurinized milk had many beneficial effects and thus may be recommended for nutritional treatment of primary or secondary hyperuricemia. Principal component analysis indicated that Akt/p-Akt and ERK/p-ERK signaling were the most discriminating variables among liver parameters investigated in this study.

\section{ACKNOWLEDGMENTS}

The experimental and laboratory work was supported by the Ministry of Education, Science and Technology, Republic of Serbia (TR 31060).

\section{REFERENCES}

Bainbridge, S. A., and J. M. Roberts. 2008. Uric acid as a pathogenic factor in preeclampsia. Placenta 29(Suppl. A):S67-72.

Bartholeyns, J., C. Peeters-Joris, H. Reychler, and P. Baudhun. 1975. Hepatic nucleases 1. Method for the specific determination and characterization in rat liver. Eur. J. Biochem. 57:205-211.

Carluccio, F., and G. Kocic. 2011. Procedimento technologico per de la producone di un alimentare dietetico composito a base di latte con livello ridoto di acido urico e purine e prodoto alimentare cosi ottenuto. F. Carluccio and G. Kocic, assignees. Italy patent IT2009PR00057 20090723.

Cencic, A., G. Kocic, G. Nikolic, D. Stojanovic, R. Pavlovic, T. Jevtovic-Stoimenov, D. Sokolovic, S. Stojanovic, S. Pajovic, R. Kocic, F. Carluccio, I. Krajnc, and A. Murua. 2011. Composite diethetic milk draught and method for production of composite milk draught with reduced level of uric acid and purine compounds. A. Cencic, assignee. Slovenia patent WO2011037545 (A1) 2011-03-31.

Cheng, T. H., J. W. Lin, H. H. Chao, Y. L. Chen, C. H. Chen, P. Chan, and J. C. Liu. 2010. Uric acid activates extracellular signalregulated kinases and thereafter endothelin-1 expression in rat cardiac fibroblasts. Int. J. Cardiol. 139:42-49.

Chieli, E., M. Saviozzi, P. Puccini, V. Longo, and P. G. Gervasi. 1990. Possible role of the acetone-inducible cytochrome P-450IIE1 in the metabolism and hepatotoxicity of thiobenzamide. Arch. Toxicol. 64:122-127.

Choi, H. K. K., E. W. Atkinson, W. K. Willett, and G. Curhan. 2004 Purine-rich foods, dairy and protein intake, and the risk of gout in men. N. Engl. J. Med. 350:1093-1103.

Dalbeth, N. S., D. Greg, G. D. A. Gamble, B. Mason, B. Pool, L. Fairbanks, F. M. McQueen, J. Cornish, I. R. Reid, and K. Pal- 
mano. 2010. Acute effect of milk on serum urate concentrations: a randomised controlled crossover trial. Ann. Rheum. Dis. 69:16771682.

Davidson, M. B., S. Thakkar, J. K. Hix, N. D. Bhandarkar, A. Wong, and M. J. Schreiber. 2004. Pathophysiology, clinical consequences, and treatment of tumor lysis syndrome. Am. J. Med. 116:546554.

Enari, M. H., H. Sakahira, K. Yokoyama, A. Okawa, A. Iwamatsu, and S. Nagata. 1998. A caspase-activated DNase that degrades DNA during apoptosis and its inhibitor ICAD. Nature 391:43-50.

Feig, D. I., D. H. Kang, and R. J. Johnson. 2008. Uric acid and cardiovascular risk. N. Engl. J. Med. 359:1811-1821.

Fujiyoshi, M., and M. Ozaki. 2011. Molecular mechanisms of liver regeneration and protection for treatment of liver dysfunction and diseases. J. Hepatobiliary Pancreat. Sci. 18:13-22.

Goldman, M. 1981. Uric acid in the etiology of psoriasis. Am. J. Dermatopathol. 3:397-404.

Hers, I., E. E. Vincent, and J. M. Tavare. 2011. Akt signalling in health and disease. Cell. Signal. 23:1515-1527.

Hewitt, L. A., C. Valiquette, and G. L. Plaa. 1987. The role of biotransformation-detoxication in acetone-, 2-butanone-, and 2-hexanone-potentiated chloroform-induced hepatotoxicity. Can. J. Physiol. Pharmacol. 65:2313-2318.

Hewitt, W R., E. M. Brown, and G. L. Plaa. 1983. Relationship between the carbon skeleton length of ketonic solvents and potentiation of chloroform-induced hepatotoxicity in rats. Toxicol. Lett. 16:297-304.

Ilowski, M., C. Putz, T. S. Weiss, S. Brand, K. W. Jauch, J. G. Hengstler, and W. E. Thasler. 2010. Augmenter of liver regeneration causes different kinetics of ERK1/2 and Akt/PKB phosphorylation than EGF and induces hepatocyte proliferation in an EGF receptor independent and liver specific manner. Biochem. Biophys. Res. Commun. 394:915-920.

Indyk, H. E., and D. C. Woollard. 2004. Determination of orotic acid uric acid, and creatinine in milk by liquid chromatography. J. AOAC Int. 87:116-122.

Jackson, L. N., S. D. Larson, S. R. Silva, P. G. Rychahou, L. A. Chen, S. Qiu, S. Rajaraman, and B. M. Evers. 2008. PI3K/AKT activation is crucial for early hepatic regeneration after partial hepatectomy . Am. J. Physiol. Gastrointest. Liver Physiol. 294:G1401G1410.

Kaput, J. 2004. Diet-disease gene interactions. Nutrition 20:26-31.

Kocic, G., L. Marinkovic, S. Stojanovic, G. Nikolic, and D. Stojanovic 2011. Adsorption filter device for production of depurinised milk. G. Kocic, assignee. Serbia patent RS 20100157 (A) 2011-04-30.

Kocic, G., G. Nikolic, D. Stojanovic, R. Pavlovic, T. Jevtovic-Stoimenov, D. Sokolovic, S. Stojanovic, S. Pajovic, and R. Kocic. 2010 Technological procedure for production of composite diethetic milk beverage draught with reduced level of uric acid and purine. G. Kocic, assignee. Serbia patent RS20090231 (A) 2010-12-31.

Kocic, G., R. Pavlovic, G. Nikolic, D. Stojanovic, T. Jevtovic, D. Sokolovic, A. Cencic, S. Stojanovic, M. Jelic, and S. Zivanovic. 2012. The effect of depurinized milk draught diet on rat serum uric acid, lipid status and haematological parameters. J. Anim. Physiol. Anim. Nutr. (Berl.) 96:640-647.

Lu, Z., and S. Xu. 2006. ERK1/2 MAP Kinases in cell survival and apoptosis. IUBMB Life 58:621-631.

Nätzker, S., T. Heinemann, S. Figueroa-Perez, B. Schnieders, R. R. Schmidt, K. Sandhoff, and G. van Echten-Deckert. 2002. cis4-Methylsphingosine phosphate induces apoptosis in neuroblastoma cells by opposite effects on p38 and ERK mitogen-activated protein kinases. Biol. Chem. 383:1885-1894.
Nix, B., and D. Wild. 2000. Data processing. Pages 239-261 in Immunoassays: A Practical Approach. J. P. Gosling, ed. Oxford University Press, Oxford, UK.

Obermayr, R. P., C. Temml, G. Gutjahr, M. Knechtelsdorfer, R. Oberbauer, and R. Klauser-Braun. 2008. Elevated uric acid increases the risk for kidney disease. J. Am. Soc. Nephrol. 19:2407-2413

Ono, H., H. Shimano, H. Katagiri, N. Yahagi, H. Sakoda, Y. Onishi, M. Anai, T. Ogihara, M. Fujishiro, A. Y. I. Viana, Y. Fukushima M. Abe, N. Shojima, M. Kikuchi, N. Yamada, Y. Oka, and T. Asano. 2003. Hepatic Akt activation induces marked hypoglycemia hepatomegaly, and hypertriglyceridemia with sterol regulatory element binding protein involvement. Diabetes 52:2905-2913.

Panseri. S., S. Soncin, L. M. Chiesa, and P. A. Biondi. 2011. A headspace solid-phase microextraction gas-chromatographic mass-spectrometric method (HS-SPME-GC/MS) to quantify hexanal on butter during storage as marker of lipid oxidation. Food Chem. 127:886-889.

Petta, S., C. Camma, D. Cabibi, V. Di Marco, and A. Craxi. 2011 Hyperuricemia is associated with histological liver damage in patients with non-alcoholic fatty liver disease. Aliment. Pharmacol. Ther. 34:757-766.

Saito, I., T. Saruta, K. Kondo, R. Nakamura, T. Oguro, K. Yamagami, Y. Ozawa, and E. Kato. 1978. Serum uric acid and the renin-angiotensin system in hypertension. J. Am. Geriatr. Soc. $26: 241-247$.

Sauer, N., R. Mosenthin, and E. Bauer. 2011. The role of dietary nucleotides in single-stomached animals. Nutr. Res. Rev. 13:1-14

Scheving, L. A., M. C. Stevenson, X. Zhang, and W. E. Russell. 2008. Cultured rat hepatocytes upregulate Akt and ERK in an ErbB2-dependent manner. Am. J. Physiol. Gastrointest. Liver Physiol. 295:G322-331.

Scientific Committee on Food. 1999. Opinion on an additional list of monomers and additives used in the manufacture of plastic materials intended to come into contact with foodstuffs until 21 March 1997. Reports of the scientific committee for food. 42nd Series. European Commission, Luxembourg.

Sculley, D. G., P. A. Dawson, R. B. Emmerson, and R. B. Gordon. 1992. A review of the molecular basis of hypoxanthine guanine phosphoribosyl transferase (HGPRT) deficiency. Hum. Genet. 90:195-207.

Séverin, S., and X. Wenshui. 2005. Milk biologically active components as nutraceuticals. Crit. Rev. Food Sci. Nutr. 45:645-656. (review).

Soncin, S., L. M. Chiesa, S. Panseri, A. Biondi, and C. Cantoni. 2009. Determination of volatile compounds of precooked prawns (Penaeus vannamei) and cultured gilthead sea bream (Sparus aurata) stored in ice as possible spoilage markers using solid phase microextraction and gas chromatography/mass spectrometry. J. Sci. Food Agric. 89:436-442.

Sørensen, L. K. 2006. Determination of phthalates in milk and milk products by liquid chromatography/tandem mass spectrometry. Rapid Commun. Mass Spectrom. 20:1135-1143.

Tiemeyer, W., M. Stohrer, and D. Giesecke. 1984. Metabolites of nucleic acids in bovine milk. J. Dairy Sci. 67:723-728.

Tomei, F., P. Giuntoli, M. Biagi, T. P. Baccolo, E. Tomao, and M. V. Rosati. 1999. Liver damage among shoe repairers. Am. J. Ind. Med. 36:541-547.

Wada, T., and J. M. Penninger. 2004. Mitogen-activated protein kinases in apoptosis regulation. Oncogene 23:2838-2849.

Whiteman, E. L., H. Cho, and M. J. Birnbaum. 2002. Role of Akt/ protein kinase $\mathrm{B}$ in metabolism. Trends Endocrinol. Metab. 13:444-451. 